\title{
BEHAVIOR OF GAMMA TIAI SUBJECTED TO IMPACT DAMAGE AND ELEVATED TEMPERATURE FATIGUE
}

\author{
T.S. Harding and J.W. Jones \\ Department of Materials Science and Engineering, University of Michigan, \\ Ann Arbor, MI 48109-2136
}

Keywords: Intermetallic; Impact; Fatigue and high temperature

\section{Introduction}

Gamma titanium aluminide has received significant attention in recent years as a candidate material for use in aerospace and industrial gas turbine engine applications. In particular, these materials offer significant weight reductions (densities are less than half that of nickel-based superalloys), high specific strength retention at elevated temperature and high specific stiffness which is particularly important in vibrating components such as blades. This combination of weight savings and good mechanical properties has led to the possibility that $\gamma$-TiAl may be a suitable replacement for nickel-based alloys, such as Inconel 718, in low pressure turbine blades without significant redesign of the blade [1]. However, the criticality of relatively low ductility, fracture toughness and fatigue crack growth resistance, must first be assessed.

It is well known that fatigue crack growth rates in $\gamma$-TiAl alloys are very sensitive to stress intensity range and that there is a small difference between threshold stress intensity range and apparent fracture toughness in these materials [2-5]. The result is limited damage tolerance and dramatic reductions in fatigue lifetime in the presence of extrinsic damage, such as that produced from an impact event. To apply a damage tolerance approach to this situation would require improved crack detection techniques and would increase the life cycle cost of the engine by decreasing the inspection interval. Using a threshold-based approach, on the other hand, would ensure that pre-existing or service induced cracks would not grow and that failure by fatigue would not occur [6].

The present study investigates the feasibility of using a threshold calculation to estimate the fatigue strength reduction caused by impact damage at elevated temperatures $\left(600^{\circ} \mathrm{C}\right)$. The results are part of a larger investigation into the feasibility of using $\gamma$-TiAl for low-pressure turbine blades.

\section{Materials and Experimental Procedure}

Two $\gamma$-TiAl alloys were investigated in the present study. The first of these is the General Electric cast duplex alloy with a composition of Ti-47.9Al-2.0Cr-1.9Nb, designated as "48-2-2" [7]. The alloy was investment cast into $12.5 \mathrm{~mm}$ thick plates. Post-processing, described in Table 1, resulted in a final duplex microstructure consisting of 60-70 $\mu \mathrm{m}$ diameter $\gamma$ grains and approximately 5 vol. $\%\left(\alpha_{2}+\gamma\right)$ lamellar colonies, shown in the optical micrograph in Figure 1a. The $\alpha_{2}\left(\mathrm{Ti}_{3} \mathrm{Al}\right)$ phase is also observed along $\gamma$ grain boundaries and at triple points. 
TABLE 1.

Processing Steps for Alloys Investigated

\begin{tabular}{lccr}
\hline Alloy & Pre-Hip HT & HIP & Post-HIP HT \\
\hline $48-2-2$ & $5 \mathrm{~h}$ at $1093^{\circ} \mathrm{C}$ & $4 \mathrm{~h}$ at $1205^{\circ} \mathrm{C}$ and $172 \mathrm{MPa}$ & $2 \mathrm{~h}$ at $1205^{\circ} \mathrm{C}$ \\
WMS & --- & $4 \mathrm{~h}$ at $1260^{\circ} \mathrm{C}$ and $172 \mathrm{MPa}$ & $50 \mathrm{~h}$ at $1010^{\circ} \mathrm{C}$ \\
\hline
\end{tabular}

The second alloy investigated was the Allied Signal cast near-fully lamellar alloy with a composition of Ti-47.3Al-2.2Nb-0.6Mn-0.45W-0.46Mo-0.23Si, designated as "WMS" [8]. Similar to the 48-2-2 alloy, the WMS alloy was investment cast into plates that were processed according to the schedule outlined in Table 1. Post-processing led to a final microstructure of $165 \mu \mathrm{m}$ diameter lamellar colonies. In addition, colonies of $15 \mu \mathrm{m}$ diameter gamma grains formed along lamellar colony boundaries. The microstructure of this alloy is shown in Figure $1 \mathrm{~b}$.

Fatigue specimens were machined from the cast plates into rectangular dogbone specimens by electro-discharge machining. This was followed by a low stress grinding operation and then a hand polish to 600 grit with $\mathrm{SiC}$ paper. Specimens were then electropolished in a perchloric acid solution. The final nominal specimen dimensions were $136 \mathrm{~mm}$ long with a $3 \mathrm{~mm} \times 6 \mathrm{~mm}$ gage section.

Impact damage was intended to simulate potential shop floor damage to a low-pressure $\gamma$-TiAl turbine blade. Though the variety of real damage of this type would be extensive, the focus of this study is on damage introduced by indenting the $3 \mathrm{~mm}$ edge of the specimens with a hardened steel wedge with a $60^{\circ}$ flank angle. Indenting was conducted using a screw-driven Instron testing machine instrumented with a load cell and computer for data acquisition.

Figure 2 shows a typical damage zone and the different damage parameters associated with it. The wedge is indented into the specimen such that the maximum load measured by the load cell reaches a peak load, P. This results in the formation of an indent with depth, $\mathrm{D}$, and tip radius, $\rho$. The tip radius is consistently on the order of $10-30 \mu \mathrm{m}$, which means that the indent can effectively be treated as a sharp notch [9]. The indent depth varies linearly with the peak impact load. If the indent depth exceeds a critical value, a crack will form at the tip of the indent with surface length, a. The effective crack length, $a_{\text {eff }}$, is defined here to be the sum of the indent depth and the indent tip crack length. The assumption is that the indent tip crack is through-thickness with a uniform crack front. This is, of

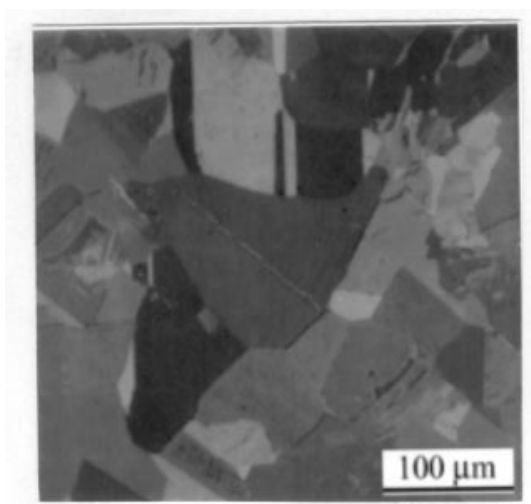

a)

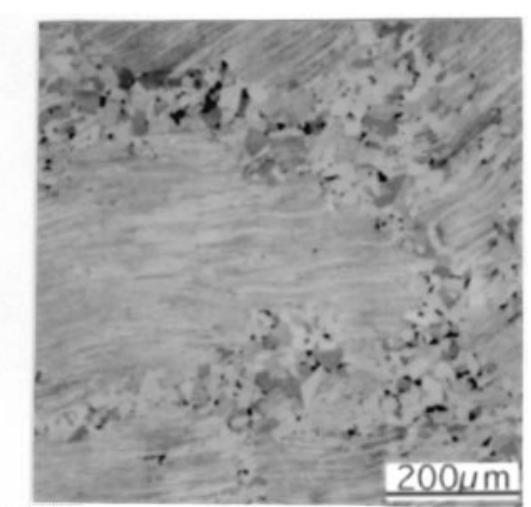

b)

Figure 1. Microstructure of the a) duplex 48-2-2 alloy and b) near-fully lamellar WMS alloy. 


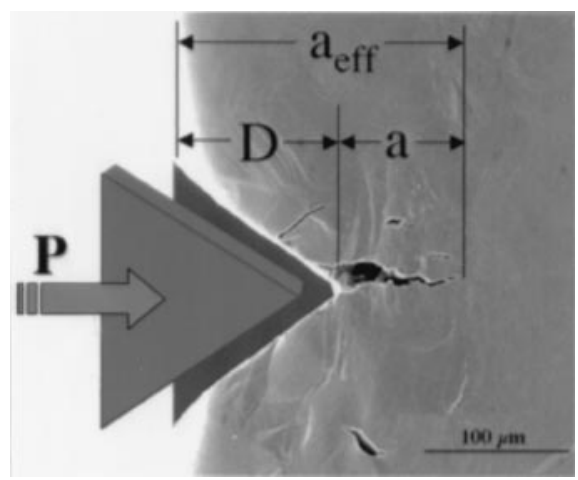

Figure 2. Typical impact damage zone showing the definition of the various damage parameters.

course, an oversimplification and work is currently being done to determine the actual shape of cracks in the interior of the specimen.

Fatigue strength reduction from impact damage was determined using a step-loading approach [10]. In this procedure a damaged specimen was tested in fatigue at a frequency of $20 \mathrm{~Hz}$ and load ratio of $\mathrm{R}=0.1$ for $10^{5}$ cycles in air. At the end of this cycle block, the maximum cyclic stress was increased by $10 \mathrm{MPa}$, while load ratio was kept constant. The stress was incrementally increased in this way every $10^{5}$ cycles until failure. The fatigue failure stress is defined as the highest maximum cyclic stress at which the specimen survived $10^{5}$ cycles. Given the flat nature of the S-N curves of $\gamma$-TiAl alloys, the fatigue failure stress is taken as a good estimate of the endurance limit.

\section{$\underline{\text { Results and Discussion }}$}

\section{Impact Damage Correlations}

As discussed above, impact damage is quantified in terms of critical damage parameters, namely indent depth and effective crack length. Figure 3 shows the correlation between these damage parameters and the impact severity, or peak load. From the figure, it can be seen that the indent depth follows a linear trend with the peak load for both alloys. However, the higher yield strength of the WMS alloy (500 MPa at $\left.23^{\circ} \mathrm{C}\right)$ compared to $48-2-2\left(330 \mathrm{MPa}\right.$ at $\left.23^{\circ} \mathrm{C}\right)$ results in smaller indent depths given the same nominal peak load.

When compared with the indent depth trend lines in Figure 3, the effective crack length trend line is a measure of the extent of cracking that occurs ahead of the indent tip. Figure 3 clearly illustrates that cracks will form in the 48-2-2 alloy at lower peak loads compared to the WMS alloy. This suggests that the 48-2-2 alloy is more susceptible to the formation of impact damage. However, examination of the effective crack length as a function of indent depth shows that in both alloys the formation of cracks occurs at an indent depth of approximately $100 \mu \mathrm{m}$, as shown in Figure 3. This is a result of a balance between the greater ductility of the duplex alloy and the ability of the lamellar microstructure of the WMS alloy to accommodate greater near indent-tip strain [11]. While it should not be overlooked that the WMS alloy exhibits greater resistance to damage at a given peak load, crack formation is based upon reaching a critical strain at the indent-tip, which in turn is based on the depth of the indent and the local microstructure.

Commonly, in the 48-2-2 alloy cracks will initially form at the indent tip by transgranular cleavage along intense planar slip lines [12], as illustrated in the micrograph of a typical damage zone in Figure 


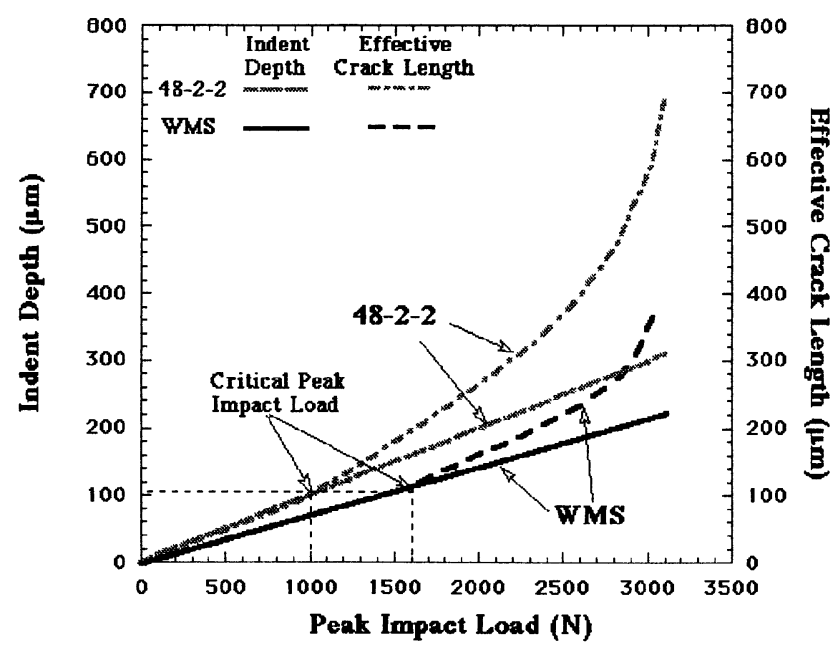

Figure 3. Trends in variation of impact damage parameters (indent depth and effective crack length) with impact severity.

4a. The crack then proceeds away from the indent tip by either transgranular cleavage, intergranular fracture or, in some cases, translamellar fracture depending on the local microstructure present at the indent tip. On average, the crack that is generated by the impact event follows the trend lines shown in Figure 3. However, in some cases the crack will propagate easily along a weak gamma grain boundary, resulting in larger crack sizes than anticipated for a given peak load.

Similar observations can be made for the WMS alloy, although in this case little intergranular fracture is observed given the near-fully lamellar microstructure. As shown in Figure 4b, indent tip cracks tend to initiate at translamellar slip lines in $\gamma$ lamellar plates, and continue to propagate by the same mechanism [13]. However, should the crack intersect an interlamellar boundary in the correct orientation, the crack could extend considerably farther than expected.

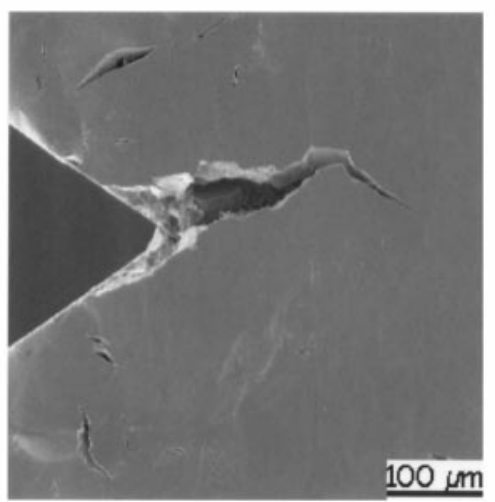

a)

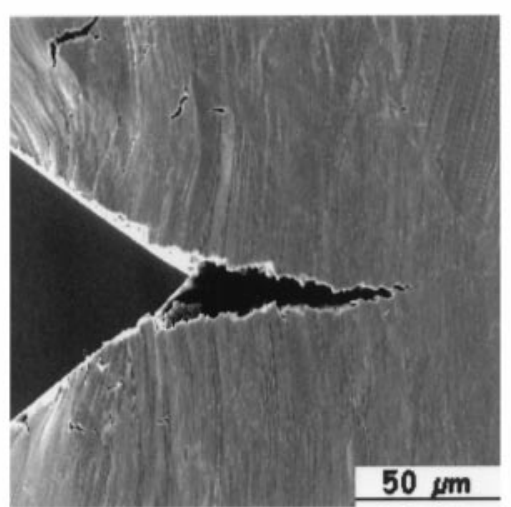

b)

Figure 4. Indent tip cracks following high severity impacts in a) 48-2-2 alloy where transgranular cleavage predominates and b) WMS where translamellar fracture predominates. 


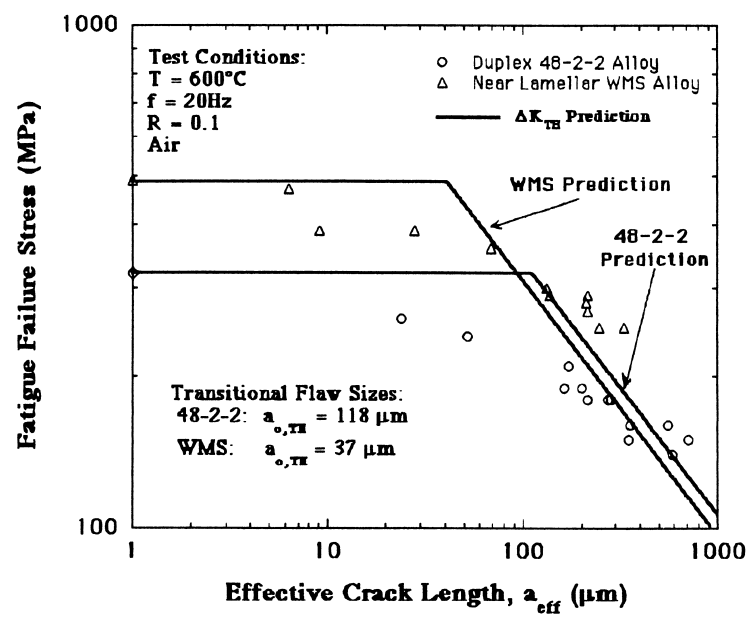

Figure 5. Kitagawa plot for $48-2-2$ and WMS alloys at $600^{\circ} \mathrm{C}$ showing correlation between impact damage and fatigue failure stress.

\section{Fatigue Strength Reductions Due to Impact Damage}

Gamma titanium aluminides suffer from lower crack growth resistance compared to more conventional titanium alloys $[14,15]$. Consequently, flaws from extrinsic sources, such as impact damage, will lead to shorter lifetimes under high cycle fatigue conditions should the threshold stress intensity range be exceeded. These circumstances suggest that a threshold-based design philosophy should be adopted when working with these alloys. To this end, the present study uses a step-loading fatigue test procedure, described earlier, to evaluate the reduction in fatigue failure stress at $600^{\circ} \mathrm{C}$ as a function of impact damage.

Results of step-loading fatigue tests are shown in Figure 5 in the form of a modified Kitagawa plot [16]. The plot compares the $600^{\circ} \mathrm{C}$ fatigue failure stress results over a wide range of effective crack lengths for both the 48-2-2 and WMS alloys. The solid lines in the plot represent the predicted behavior based upon a measured fatigue failure stress for undamaged material (horizontal line) and a threshold stress intensity range based estimation of fatigue failure stress for damaged specimens (sloped line). The point at which these two lines intersect is termed the transitional flaw size, which represents the physical crack size for transition between damage independent and damage dependent fatigue behavior. The transitional flaw sizes for the 48-2-2 and WMS alloys were found to be $118 \mu \mathrm{m}$ and $37 \mu \mathrm{m}$ respectively.

Theoretically, below the transitional flaw size damage has no effect on the fatigue failure stress. Therefore, for low severity impacts the fatigue failure stress should be the same as that of undamaged material. The fatigue failure stress of undamaged material was determined using the step-test procedure. For the 48-2-2 and WMS alloys at $600^{\circ} \mathrm{C}$, these values were found to be $310 \mathrm{MPa}$ and $490 \mathrm{MPa}$ respectively.

At damage levels greater than the transitional flaw size, the fatigue failure stress should show a strong correlation with the threshold stress determined from long-crack threshold data. The long-crack threshold stress is determined using a linear elastic fracture mechanics calculation of the form:

$$
\sigma_{T H}=\frac{\Delta K_{T H}}{(1-R) Y \sqrt{\pi a_{e f f}}}
$$


where $\Delta \mathrm{K}_{\mathrm{TH}}$ is the long-crack threshold stress intensity range, $\mathrm{R}$ is the load ratio, $\mathrm{Y}$ is the geometrical factor and $\mathrm{a}_{\text {eff }}$ is the effective crack length. As Figure 5 shows, there is a good correlation between this threshold-based calculation and the fatigue failure stress determined from experiments for the 48-2-2 alloy. However, for the WMS alloy the threshold-based approximation is somewhat conservative. This deviation could be caused by compressive residual stresses at the indent tip that would reduce the crack driving force for crack growth and lead to higher measured fatigue failure stress levels. Another possibility is that the effective crack length measurements are not an accurate measure of the impact damage in the specimen interior. An analytical examination of these effects is currently underway.

Despite its lamellar microstructure, the near-threshold crack growth behavior of the WMS alloy is similar to that of the 48-2-2 alloy. Consequently, the fatigue failure stresses calculated from equation (1) were nearly the same for both alloys for a given effective crack length. Actual step-test results indicate that the WMS alloy does have a higher fatigue failure stress than 48-2-2; however, design criteria based on a threshold-based approach would negate this advantage.

The fatigue failure stress does not transition from the damage independent region to the damage dependent region as abruptly as the Kitagawa plot would suggest. Instead, the data tend to approach the fatigue failure stress of the undamaged material asymptotically. This behavior has been observed by others and is generally attributed to a small crack phenomenon [17,18]. In the 48-2-2 alloy this small crack behavior is limited to cracks less than $300 \mu \mathrm{m}$ in size, approximately four to five times the grain size. In the WMS alloy, this behavior is limited to cracks on the order of $80 \mu \mathrm{m}$ in size. However, potential residual stress effects may conceal the actual crack size range over which this small crack effect dominates.

\section{Conclusions}

1) A threshold-based approximation of fatigue failure stress is possible in impact-damaged duplex Ti-47.9Al-2.0Cr-1.9Nb and near-fully lamellar Ti-47.3Al-2.2Nb-0.5Mn-0.4W-0.4Mo-0.23Si at $600^{\circ} \mathrm{C}$ when impact damage is severe. However, questions regarding residual stresses, crack geometry and small cracks remain to be fully explained.

2) Despite a higher fatigue failure stress in the undamaged condition, the predicted fatigue failure stress of the near-fully lamellar alloy is almost the same as that of the duplex alloy when severe impact damage is introduced. This is attributed to similar threshold stress intensity factor ranges for the two alloys, and has the effect of eliminating the advantage of higher fatigue strength enjoyed by the WMS alloy when a threshold-based design approach is used.

3) When impact damage is near or below the transitional flaw size of the Kitagawa plot, the threshold-based approximation provides a non-conservative estimate of fatigue failure stress. This region of small crack behavior is limited to cracks smaller than $300 \mu \mathrm{m}$ in the duplex alloy and 80 $\mu \mathrm{m}$ in the lamellar alloy.

\section{$\underline{\text { Acknowledgments }}$}

Funding for this work was provided by the Air Force Office of Scientific Research under grant F49620-95-1-0359. The valuable contributions of Drs. James Larsen and Andrew Rosenberger of Wright Patterson Air Force Base are gratefully acknowledged. The authors would also like to thank Mr. Volus McKenna of Carnegie Mellon University for conducting the impact tests. 


\section{$\underline{\text { References }}$}

1. C. M. Austin and T. Kelly, in Structural Intermetallics, ed. Darolia et al, pp. 143-150, TMS, Warrendale, PA (1995).

2. S. J. Balsone, J. M. Larsen, D. C. Maxwell, and J. W. Jones, Mater. Sci. Eng. A. 192/193, 457 (1995).

3. B. D. Worth, J. M. Larsen, S. J. Balsone, and J. W. Jones, Metall. Trans. A. 28, 825 (1995).

4. K. T. Venkataswara, Y-W Kim, C. L. Muhlstein, and R. O. Ritchie, Mater. Sci. Eng. A. 192/193, 474 (1995).

5. P. Bowen, A. S. Chave, and A. W. James, Mater. Sci. Eng. A. 192/193, 443 (1995).

6. I. J. Perrin, Gas Turbine Engine Technology, pp. 148-158, Institute of Metals, London (1998).

7. S. C. Huang, U.S. Patent 5,076,858, (1991).

8. P. R. Bhowal, H. F. Merrick, and D. E. Larsen, Jr., Mater. Sci. Eng. A. 192/193, 685 (1995).

9. R. A. Smith and K. J. Miller, Int. J. Mech. Sci. 20(10), 201 (1978)

10. J. A. Collins, Failure of Materials in Mechanical Design, John Wiley and Sons, New York (1993).

11. K. S. Chan and Y.-W. Kim, Metall. Trans. A. 23, 1663 (1992).

12. T. M. Pollock, D. R. Mumm, K. Muraleedharan, and P. L. Martin, Scripta Mater. 35, 1311 (1996).

13. K. S. Chan and Y-W Kim, Metall. Trans. A. 25, 1217 (1994).

14. S. C. Huang and J. C. Chestnutt, Intermetallic Compounds, vol. 2, Practice, ed. J. H. Westbrook and R. L. Fleischer, pp. 73-90 (1994).

15. J. Kumpfert, Y-W Kim, and D. M. Dimiduk, Mater. Sci. Eng. A. 192/193, 465 (1995).

16. H. Kitagawa and S. Takahashi, in Proceedings of the 2nd International Conference on Mechanical Behavior of Metals, pp. 627-631, American Society for Metals, Metals Park, OH (1976).

17. D. Taylor and J. F. Knott, Fract. Eng. Mater. Struct. 4, 147 (1981).

18. K. Tanaka, Y. Nakai, and M. Yamashita, Int. J. Fract. 17, 519 (1981). 